\title{
Effect of Magnetic Field on the wall Permeable Channel Flow with Convective Cooling
}

\author{
Issa Shabani Mfinanga and Aziza Iddi \\ Department of Mathematics, Informatics and Computational Sciences \\ Sokoine University of Agriculture (SUA) \\ Morogoro, Tanzania
}

\begin{abstract}
This study aimed at making an investigation on the effect of the magnetic field on second law analysis for magnetohydrodynamic (MHD) permeable channel flow with convective cooling. Specifically, the study intended to develop a flow model for a case of nanofluid in a channel, determining the effect of different parameters on velocity and temperature of nanofluid and to determine the effect of the magnetic field on the channel flow of nanofluid.

In this study, the appropriate mathematical model for the problem was derived from the laws of conservation, momentum and energy balance where both first and second laws of thermodynamics are utilized to analyze the model problem. Using the discretization finite difference method together with the Runge-Kutta Fehlberg integration scheme, the governing partial differential equations are solved numerically and implemented on the Computer using Matlab software. The findings showed that the alumina water nanofluid tended to flow quicker than copper water nanofluid and the velocity profile increased with Hartmann number but decreased with the quantity of nanoparticle volume fraction and magnetic field.
\end{abstract}

Keywords: Channel, Nano fluids, Magnetic field, Permeability, Injection, Suction.

\section{INTRODUCTION}

In recent times, there has been a renewed interest in the study of the MHD (Magneto hydrodynamic) flow of conducting fluid through a permeable channel between two parallel plates, which has gained attention of scientists and engineers in the field. This is due to its great applications in various branches of industries and engineering like MHD pumps, MHD generators, accelerators, electrostatic precipitation, polymer technology, geothermal energy extraction, purification of crude oil, nuclear reactors, plasma studies, petroleum industries, the boundary control in the field of aerodynamics and blood flow problems. Based on the application, various mathematical models have been formulated to study the behavior of the flow.

Nanoparticle-fluid suspensions are just called Nanofluids, which are obtained by dispersing nanometer sized particles in a conventional base fluid like oil, water, ethylene glycol. Nanoparticles of materials like metallic oxides $\left(\mathrm{Al}_{2} \mathrm{O}_{3}, \mathrm{CuO}\right)$, nitride ceramics $(A l N, \operatorname{SiN})$, carbide ceramics $(\mathrm{SiC}, \mathrm{TiC})$, and metals $(\mathrm{Cu}, \mathrm{Ag}, \mathrm{Au})$ are mostly employed in the preparation of nanofluids. These nanofluids have been found to possess an enhanced thermal conductivity (Shyam et al., 2008; Choi et al., 2001; Eastman et al., 2001) as well as improved heat transfer performance (Xuan et al., 2003; Yu et al., 2003; Vassalo et al., 2004; Artus, 1996) at low concentrations of nanoparticles. 


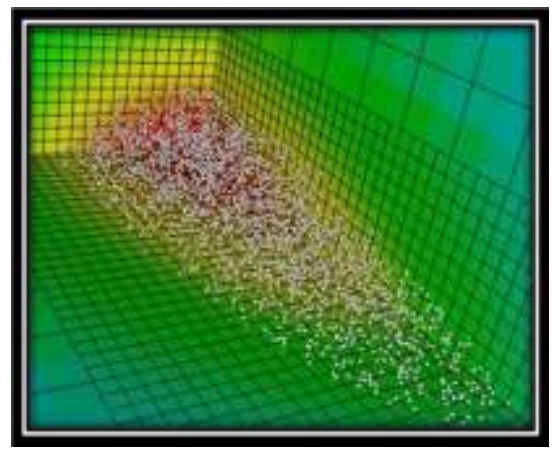

Figure1: Nanoparticles image

https://media4.picsearch.com/is?utljD4_bAEnrEs6H_34R28quixwjJhNDPU9n4eHtA\&height=277.

A fluid with high viscosity resists motion because its molecular makeup give a lot of internal friction, on the other hand, a fluid with low viscosity flow easily because its molecular makeup results in very little friction when it is in motion. For example, honey has a high viscosity than water.

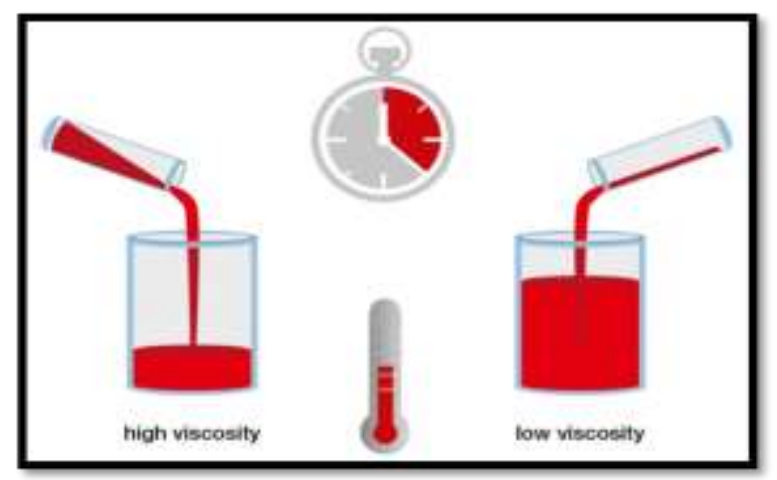

Figure 2: Comparing high viscosity fluid low viscosity fluid.

A measure of unavailable energy in a closed thermodynamic system that is also considered to be the measure of system's disorders, that is a property of the system's state, that varies directly with any reversible change in heat in the system and inversely with the temperature of the system broadly; the degree of disorder or uncertainty in a system. The idea of Entropy gives the mathematical way to encode the intuitive notion of which processes are impossible, even though they would not violet the fundamental law of conservation of energy. Farther, the term entropy can be defined as the measure of the level of disorder in a bounded but dynamics system in which the energy is transferred;

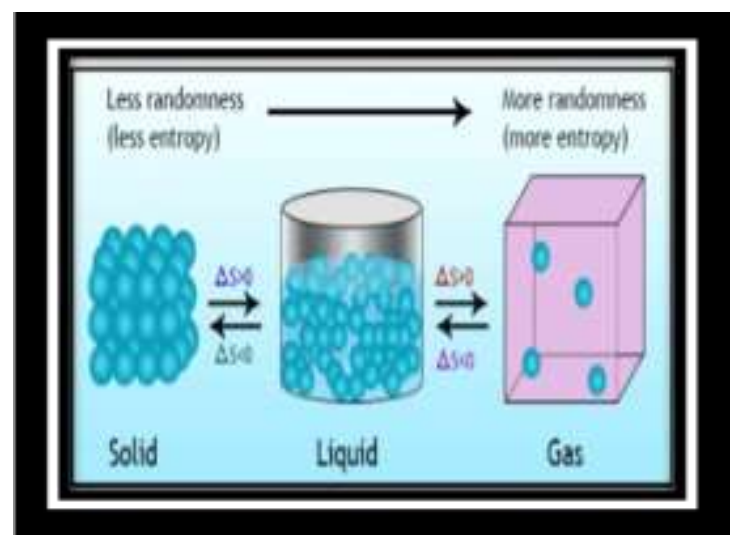

Figure 3: Entropy generation

Channel flow is the fluid flow within the conduit with a free surface known as channel. There are two types of channel flow namely open channel flow and pipe flow. 


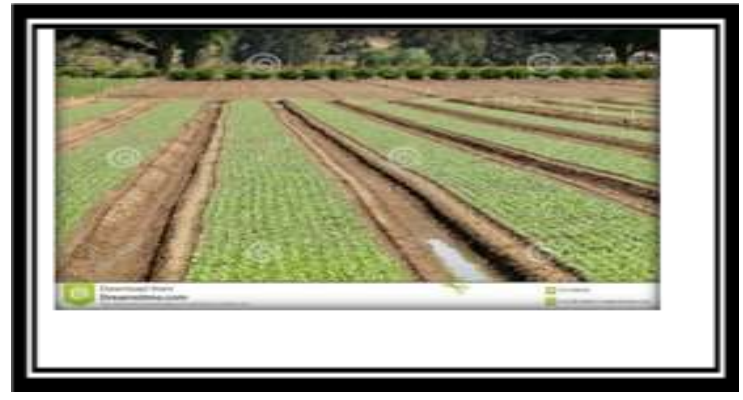

Figure 4: Open channel flow.

https://encryptedtbn0.gstatic.com/images?q=tbn:ANd9GcQ4eMb_fjITpF_K8MESnc613D71tBLnf8O3wDvVrkFLheIt2QNG

Magneto-hydrodynamics (MHD) is the study of the magnetic properties and behavior of electrically conducting fluids. Examples of such conducting fluids (magnetofluids) include plasmas, liquid metals, salt water, and electrolytes etc. The word "Magnetohydrodynamics" is derived from magneto meaning magnetic field, hydro meaning water, and dynamics meaning movement

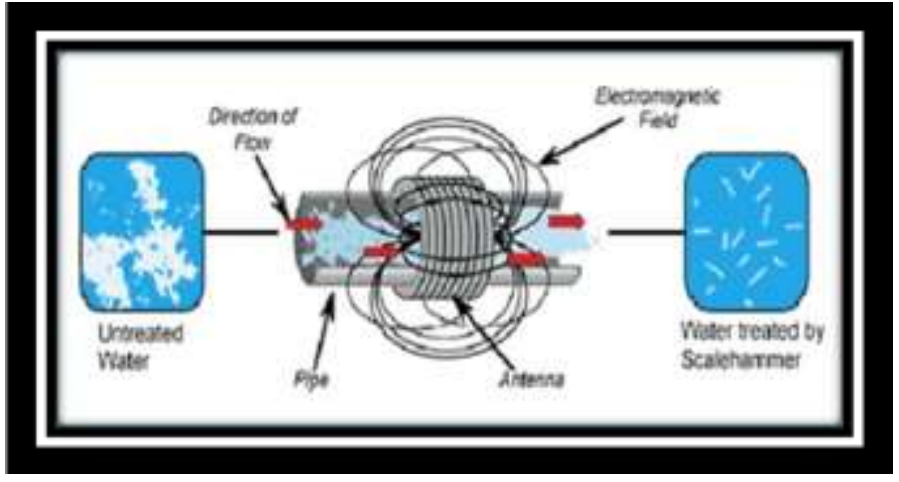

Figure 5: MHD Technology.

http://www.assignmentpoint.com/wp content/uploads/2017/04/Magnetohydrodynamics0.jpg

A survey of MHD studies shows that, an extensive theoretical work has carried out on the hydromagnetic fluid flow in a channel under various situations e.g., Hartmann, Borkakati and Pop (1984), Makinde (2003), etc. Meanwhile, Beavers and Joseph in their experimental work on boundary conditions at a naturally permeable wall confirmed the existence of slip at the interface separating the flow in the channel and the permeable boundaries. The importance of slip velocity on ultra-filtration performance has been well illustrated by Singh and Lawrence. Pal et al. investigated the effect on slip on longitudinal dispersion of tracer particles in a channel bounded by porous media. The problem of laminar flow in channels of slowly varying width permeable boundaries was investigated in Makinde ([10]).

Mkwizu, Matofali and Ainea, (2018), they did a research on Entropy generation in a variable viscosity transient generalized Couette flow of nanofluids with Navier slip and convective cooling in which the flow structure, heat transfer and entropy generation in unsteady channel flow in a variable viscosity transient generalized Couette flow of nanofluids with Navier slip and convective cooling water based nanofluids with convective heat exchange with the ambient at the walls were numerically investigated. Using a semi discretization finite difference method together with Runge-Kutta Fehlberg integration scheme, and they came to find out that, the nanofluid velocity and temperature profiles increase with an increase in time, Eckert number but decreases as space and Biot number increase. The nanofluid temperature decreases with an increase in time, space and Biot number, The nanoparticles concentration increases and decreases at the lower wall and upper wall respectively with an increase in, time and motion of particles. The constant entropy generation within the channel and increase in entropy generation at the upper wall was examined with increase in Biot number, nanoparticle fraction $A b$ and thermophoresis $N(t)$ and they generally, concluded that with careful combination of parameter values, the entropy production within the channel flow in a variable viscosity transient generalized Couette flow of nanofluids with Navier slip and convective cooling water based nanofluids could be minimized.

Medina, A. (2016) conducted a research on the numerical investigation of entropy generation in micro channels heat sink with different shapes, in this study of numerical simulation of entropy generation in MCHS using water as a base fluid in which three different single shapes namely square, hexagonal and circular were examined. The very general results obtained were that, total 
entropy generation and the entropy generation number tend to decrease with an increase in the Reynolds number. And also the increase in the heat flux leads to an increase in the total entropy generation together with entropy generation number.

Also another research done by (Kareem et al,. 2017) on Entropy generation rate in unsteady buoyancy-driven hydro magnetic couple stress fluid flow through a porous channel showed a great result yet very useful to other researchers in which they come to investigate that, the entropy generation rate in the fluid model depends on the internal forces between the fluid parcels. Also it was found out that the presence of the Lorentz force in the fluid could be used to carry out a speed control mechanism in the studied fluid system as an increase in magnetic field in the fluid lowers velocity.

Analysis of entropy generation rate in a hydro magnetic Couette flow of nanofluids inside a rotating channel as done by (Marie and Couette, no date), showed that, the entropy generation characteristics of hydro magnetic nanofluid flow in a horizontal rotating channel in the presence of a transverse magnetic field is affected by both magnetic field and rotation rate that show significant effect on the velocity and heat transfer profiles in the system with $\mathrm{Cu}$-water nanofluid presenting the maximum velocity and heat transfer efficiency. Also the temperature of the nanofluid tend to increases with an increase in either solid volume fraction or Eckert number as per their investigation.

Baskaya, Komurgoz and Ozkol, (2017)Investigated on the effect of oriented magnetic field on Entropy Generation in an Inclined Channel Filled with Ferro fluids in which they came up with the conclusion that an increase in magnetic field density compresses the flow field significantly and such an effects get stronger as the volume fraction of nanoparticles in nanofluids increases. Also they came to know that the temperature and velocity increases as the inclination of the channel increases but such tendency get reduced with either larger intensity of magnetic field or larger volume fraction of nanofluids. The velocity decreases with an increase in volume fraction of nanoparticles. Yet, the minimum entropy generation was observed around when the magnetic field angle was perpendicular to the channel flow.

Das, Jana and Chamkha, (2015) Investigated on entropy generation in a magneto-hydrodynamic (MHD) pseudo-plastic nanofluid flow through a porous channel with convective heating. They considered three different types of nanoparticles, namely copper, aluminum oxide and titanium dioxide, together with pseudo-plastic carboxymethyl cellulose (CMC), yet water was used as base fluids, the governing equations was solved numerically by shooting technique coupled with Runge-Kutta scheme. The effects of the pertinent parameters on the fluid velocity, temperature, entropy generation, Bejan number as well as the shear stresses at the channel walls were presented graphically and analyzed in detail. It was possible to determine optimum values of magnetic parameter, power-law index, Eckert number and Boit number which lead to a minimum entropy generation rate.

Vyas and Srivastava (2013) Investigate the combined effect of a transverse magnetic field and radiative heat transfer to unsteady flow of a conducting optically thin fluid through a channel filled with saturated porous medium and non-uniform walls temperature. On the basis of certain simplified assumptions, the fluid equations of continuity, momentum and energy were found.

Mkwizu, Makinde and Nkansah-Gyekye ( 2015), they had a research to investigate on how navier slip and wall permeability affects entropy generation in unsteady generalized couette flow of nanofluids with convective cooling. And they came up with the number of result including the following that, the increase in nanoparticles volume fraction and Reynolds number leads to velocity profile decrease. At the same time, the nanofluid velocity profile tends to increase with an increase in the pressure gradient. The temperature profile increases with an increase in the nanoparticles volume fraction, slip parameter and Eckert number, although a decrease in temperature profile was observed with an increase in Biot number. Also, Skin friction increases with an increase in nanoparticles volume fraction, slip parameter and Reynolds number but decreases with an increase in pressure gradient. The same results were obtained for the Nusselt number. An increase in the entropy generation rate was observed with an increase in nanoparticles volume fraction and slip parameter. It falls near the lower wall and rises near the upper wall with an increase in Biot number. The Bejan number increased with time at the lower and upper walls but slight decreased at the channel Centre line. It increases at the walls with an increase in nanoparticles volume fraction.

Mkwizu and Makinde(2015) conducted a study on the Numerical investigation into entropy generation in a transient generalized Couette flow of nanofluids with convective cooling. In which they found the results that, the -water nanofluid tended to flow quicker than $\mathrm{Cu}$-water nanofluid and the velocity profile increased with but decreased with and .The temperature of -water nanofluid raised higher than -water nanofluid and the temperature profile increased with and but decreased with .Also, temperature profile increased near the lower wall and decreased as it was approaching the upper wall with an increase in , the same was observed with an increase in . -water Nano fluid produced higher Nusselt number than -water Nano fluid and the Nusselt number increased with and but decreased. The -water nanofluid produced higher entropy generation rate than -water nanofluid near the lower wall, but as it approached the upper wall, -water nanofluid produced higher entropy generation rate than -water nanofluid. The entropy generation increased with and, it decreased with . 
Mkwizu, Makinde and Nkansah-Gyekye (2015) did a research on the Second Law Analysis of Buoyancy Driven Unsteady Channel Flow of nanofluids with Convective Cooling. They found that the -water nanofluid tends to flow faster than -water nanofluid and the velocity profile increases with Ec, Gr, A but decreases with $\phi$. The temperature of -water nanofluid rises higher than -water nanofluid and the temperature profile increases with Ec, Gr, A but decreases with $\phi$ and $\mathrm{Bi}$. The $\mathrm{Cu}$-water nanofluid produces higher skin friction than -water nanofluid and the skin friction increases with Ec, Gr but decreases with $\phi$ and $\mathrm{Bi}$. The water nanofluid produces higher Nusselt number than -water nanofluid and the Nusselt number increases with Ec, Gr but decreases with $\phi$ and $\mathrm{Bi}$. The -water nanofluid produces higher entropy than -water nanofluid and the skin generation increases with Ec, Gr, A but decreases with $\phi$ and Bi. Fluid friction irreversibility dominants the channel centreline region while the effects of heat transfer irreversibility near the walls increases with Gr, Ec, A but decreases with $\phi$ and Bi.

Makinde and Tshehla, (2017)Irreversibility Analysis of MHD Mixed Convection Channel Flow of nanofluid with Suction and Injection. The results was that, velocity profiles increases with and but decreases with, and .

\section{MATHEMATICAL MODEL}

The steady hydro magnetic flow of viscous flow conducting incompressible fluid in a channel with permeable walls is considered in the presence of convective cooling system, an imposed transverse magnetic field of strength $\beta_{o}$, an induced electric field $E_{z}$. The induced electric field is assumed to be small when compared to the applied magnetic field and is thus neglected. Both fluid injection and suction are assumed to take place at the lower and upper walls respectively as shown in the figure bellow. The channel wall Temperature is non uniform with temperature $T_{o}$ at the lower wall and $T_{w}$ at the upper wall such that $T_{w}>T_{o}$.

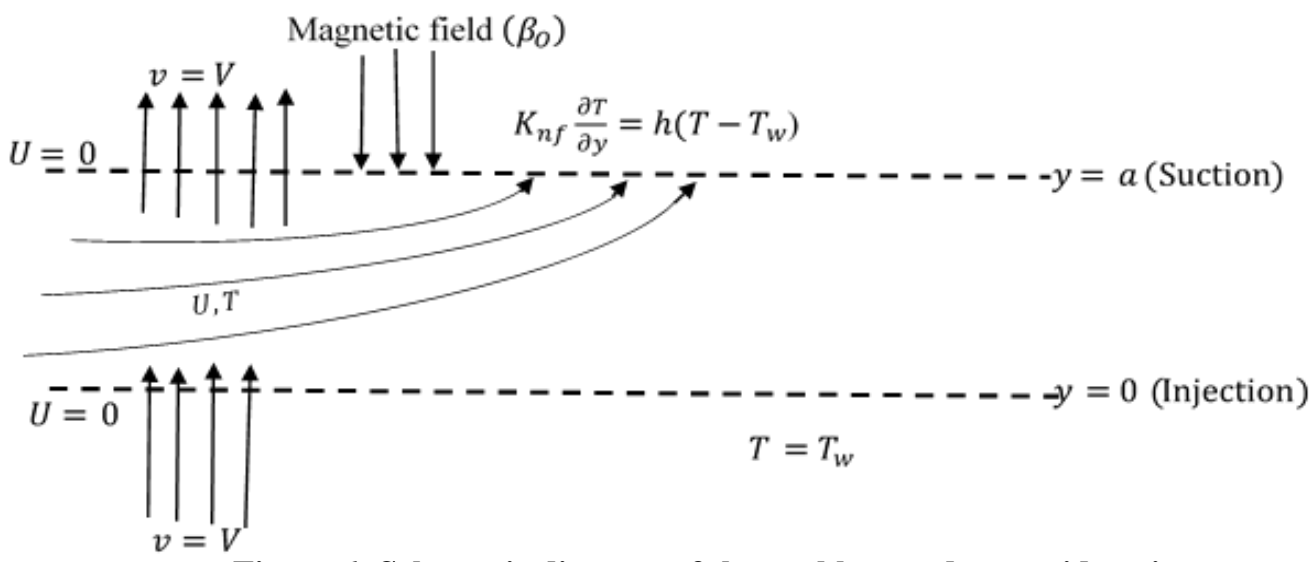

Figure 6: Schematic diagram of the problem under consideration.

The governing equations for the nanofluids momentum and energy in one dimension with assumption above can be written as follows

$$
\begin{aligned}
& \frac{\partial u}{\partial t}+V \frac{\partial u}{\partial y}=\frac{-1}{\rho_{n f}} \frac{\partial p}{\partial x}+\frac{\mu_{n f}}{\rho_{n f}} \frac{\partial^{2} u}{\partial y^{2}}-\frac{\sigma_{w} \beta_{o}}{\rho_{f}} \\
& \frac{\partial T}{\partial t}+V \frac{\partial T}{\partial y}=\alpha_{n f} \frac{\partial^{2} T}{\partial y^{2}}+\alpha_{n f} \frac{\mu_{n f}}{k_{n f}}\left(\frac{\partial u}{\partial y}\right)^{2}
\end{aligned}
$$

Where $u$ is the nanofluid velocity in the $x$-direction, $T$ is the temperature of the nanofluid, $p$ is the nanofluid pressure, $t$ is the time, $a$ is the channel half width, $T_{w}$ is the ambient temperature, $\mu_{n f}$ is the dynamic viscosity of the nanofluid, $k_{n f}$ is the nanofluid thermal conductivity, $\rho_{n f}$ is the density of nanofluid and $\alpha_{n f}$ is the thermal diffusivity of the nanofluid as given by (Abu-Nada, 2008, Mkwizu et al, 2015, shahi et al 2011, Makinde, 2013). The dynamic viscosity of nanofluid will be assumed to be temperature independent. 
International Journal of Advances in Scientific Research and Engineering (ijasre), Vol 6 (5), May-2020

$$
\begin{gathered}
\mu_{n f}=\frac{\mu_{f}}{(1-\varphi)^{2.5}}, \quad \rho_{n f}=(1-\varphi) \rho_{f}+\varphi \rho_{s} \quad, \alpha_{n f}=\frac{k_{n f}}{\left(\rho c_{p}\right)_{n f}}, \tau=\frac{\left(\rho c_{p}\right)_{s}}{\left(\rho c_{p}\right)_{f}} \\
\frac{k_{n f}}{k_{f}}=\frac{\left(k_{s}+2 k_{f}\right)-2 \varphi\left(k_{f}-k_{s}\right)}{\left(k_{s}+2 k_{f}\right)+\varphi\left(k_{f}-k_{s}\right)},\left(\rho c_{p}\right)_{n f}=(1-\varphi)\left(\rho c_{p}\right)_{f}+\varphi\left(\rho c_{p}\right)_{s}
\end{gathered}
$$

The quantity of nanoparticle volume fraction will be represented by $\varphi\left(\varphi=0\right.$ corresponds to a regular fluid), $\rho_{f}$ and $\rho_{s}$ are the densities of the base fluid and nanoparticles respectively, $K_{f}$ and $K_{s}$ represents thermal conductivity of the base fluid and nanoparticles respectively, $\left(\rho c_{p}\right)_{f}$ and $\left(\rho c_{p}\right)_{s}$ stands for heat capacitance of the base fluid and nanoparticle respectively. A very notable thing is that, the use of $K_{n f}$ is highly restricted to spherical nanoparticles as it does not account for other shapes of nanoparticles as per (Maxwell, 1904; Tiwari \& Das 2007; Makinde 2012). The initial and boundary conditions for the problem are;

$u(y, 0)=0, u(0, t)=0,, T(y, 0)=T_{w}, T(0, t)=T_{w}$

$-k_{f} \frac{\partial T}{\partial y}(a, t)=h\left(T(a, t)-T_{w}\right), u(a, t)=0$

where, $T_{w}$ is the ambient temperature which also corresponds to the lower wall temperature.

Table 1: Thermophysical properties of water, copper and alumina at the reference temperature as per (Abu-Nada, 2008; Shahi et al, 2011; Mkwizu et al, 2015)

\begin{tabular}{|l|l|l|l|}
\hline Physical properties & Fluid phase Water & Copper $(\mathrm{Cu})$ & Alumina $\left(\mathrm{Al}_{2} \mathrm{O}_{3}\right)$ \\
\hline$c_{p}(\mathrm{~J} / \mathrm{kgK})$ & 4179 & 385 & 765 \\
\hline$\rho\left(\mathrm{kg} / \mathrm{m}^{3}\right)$ & 997.1 & 8933 & 3970 \\
\hline$k(\mathrm{~W} / \mathrm{mK})$ & 0.613 & 401 & 40 \\
\hline
\end{tabular}

The following dimensionless variables and parameters are to be introduced into equation (1) to equation (6).

$$
\left.\begin{array}{l}
\theta=\frac{T-T_{w}}{T_{w}}, W=\frac{u}{U}, \bar{t}=\frac{t U}{a}, V_{f}=\frac{\mu_{f}}{\rho_{f}}, \bar{p}=\frac{p a}{\mu_{f} U}, \eta=\frac{y}{a}, X=\frac{x}{a} \\
\operatorname{Pr}=\frac{\mu_{f} c_{p f}}{k_{f}}, E c=\frac{U^{2}}{c_{p f} T_{w}}, \tau=\frac{\left(\rho c_{p}\right)_{s}}{\left(\rho c_{p}\right)_{f}}, m=\frac{\left(k_{s}+2 k_{f}\right)+\varphi\left(k_{f}-k_{s}\right)}{\left(k_{s}+2 k_{f}\right)-2 \varphi\left(k_{f}-k_{s}\right)} \\
\operatorname{Re}=\frac{U a}{V_{f}}, H a=\frac{\sigma_{w} \beta_{o}^{2} a^{2}}{\mu_{f}}, A=-\frac{\partial \bar{p}}{\partial X}
\end{array}\right\}
$$


International Journal of Advances in Scientific Research and Engineering (ijasre), Vol 6 (5), May-2020

The dimensionless governing equations together with their appropriate initial and boundary conditions can be discretized as follows:

$$
\begin{aligned}
& \frac{\partial W}{\partial \bar{t}}=\frac{A}{\operatorname{Re}\left(1-\varphi+\frac{\varphi \rho_{s}}{\rho_{f}}\right)}+\frac{1}{\operatorname{Re}\left(1-\varphi+\frac{\varphi \rho_{s}}{\rho_{f}}\right)(1-\varphi)^{2.5}} \frac{\partial^{2} W}{\partial \eta^{2}}-\frac{a}{\operatorname{Re}} \frac{\partial W}{\partial \eta}-\frac{H a}{\beta_{o} U \operatorname{Re}} \\
& \frac{\partial \theta}{\partial \bar{t}}=\frac{1}{\operatorname{Re} m \operatorname{Pr}((1-\varphi)+\varphi \tau)} \frac{\partial^{2} \theta}{\partial \eta^{2}}+\frac{E c}{\operatorname{Re}((1-\varphi)+\varphi \tau)(1-\varphi)^{2.5}}\left(\frac{\partial W}{\partial \eta}\right)^{2}-\frac{a}{\operatorname{Re}} \frac{\partial \theta}{\partial \eta}
\end{aligned}
$$

The initial and boundary conditions for equations are as follows;

$$
\begin{aligned}
& W(\eta, 0)=\theta(\eta, 0)=0 \\
& W(0, \bar{t})=\theta(0, \bar{t})=0 \\
& W(1, \bar{t})=1, \frac{\partial \theta}{\partial t}(1, \bar{t})=-m \beta i \theta(1, \bar{t})
\end{aligned}
$$

Where, $\beta i$ is the Biot number, $\operatorname{Pr}$ is the Prandtl number, $E c$ is the Eckert number, $A$ is the pressure gradient parameter and $\mathrm{Ha}$ is the Hartmann number.

\section{NUMERICAL PROCEDURE}

Using a discretization finite difference method, the nonlinear initial boundary value problem (IBVP) in equation (8) and (9) can be solved numerically. We use partition of the spatial interval $0 \leq \eta \leq 2$ into $N$ equal parts and define the grid size $\Delta \eta=\frac{1}{N}$ and the grid point $\eta_{i}=(i-1) \Delta \eta$ and $1 \leq i \leq N+1$. The first and second partial differential equations were discretized using the central difference method. Let $W_{i}(t) a n d \theta_{i}(t)$ be the approximation of $W\left(\eta_{i}, t\right)$ and $\theta\left(\eta_{i}, t\right)$ then the semi-discrete system for the problem becomes;

$\frac{d W_{i}}{d \bar{t}}=\frac{A}{\operatorname{Re}\left(1-\varphi+\frac{\varphi \rho_{s}}{\rho_{f}}\right)}+\frac{W_{i+1}-2 W_{i}+W_{i-1}}{\operatorname{Re}\left(1-\varphi+\frac{\varphi \rho_{s}}{\rho_{f}}\right)(1-\varphi)^{2.5}(\Delta \eta)^{2}}-\frac{a}{\operatorname{Re}}\left(\frac{W_{i+1}-W_{i-1}}{2 \Delta \eta}\right)-\frac{H a}{\beta_{o} U \operatorname{Re}}$

$\frac{d \theta}{d \bar{t}}=\frac{\theta_{i+1}-2 \theta_{i}+\theta_{i-1}}{\operatorname{Re} m \operatorname{Pr}((1-\varphi)+\varphi \tau)(\Delta \eta)^{2}}+\frac{E c}{\operatorname{Re}((1-\varphi)+\varphi \tau)(1-\varphi)^{2.5}}\left(\frac{W_{i+1}-W_{i-1}}{2 \Delta \eta}\right)^{2}-\frac{a}{\operatorname{Re}}\left(\frac{\theta_{i+1}-\theta_{i-1}}{2 \Delta \eta}\right)$

With initial condition:

$$
W_{i}(0)=\theta_{i}(0)=0,1 \leq i \leq N+1
$$

and boundary condition:

$$
\begin{aligned}
& W_{1}=0, \theta_{1}=0, W_{i+1}=1 \\
& \theta_{i+1}=\theta_{i}(1-m \beta i \Delta \eta)
\end{aligned}
$$




\section{RESULTS AND DISCUSSION}

In this study, the performed numerical solutions of the above Model were done by using some chosen physically meaningful values for the parameters. The Prandtl number of the base fluid (water) was kept constant at 6.2 and the effect of solid volume fraction was investigated in the range of $0 \leq \phi \leq 0.3$. The results are illustrated graphically in figures bellow.

\subsection{Effects of parameter variation on velocity profile.}

In this part the key parameters effect on the velocity profiles are presented in figures shown bellow in which we depicted the variation of velocity profile of nanofluids for a given set of parameter values as space and time increases.

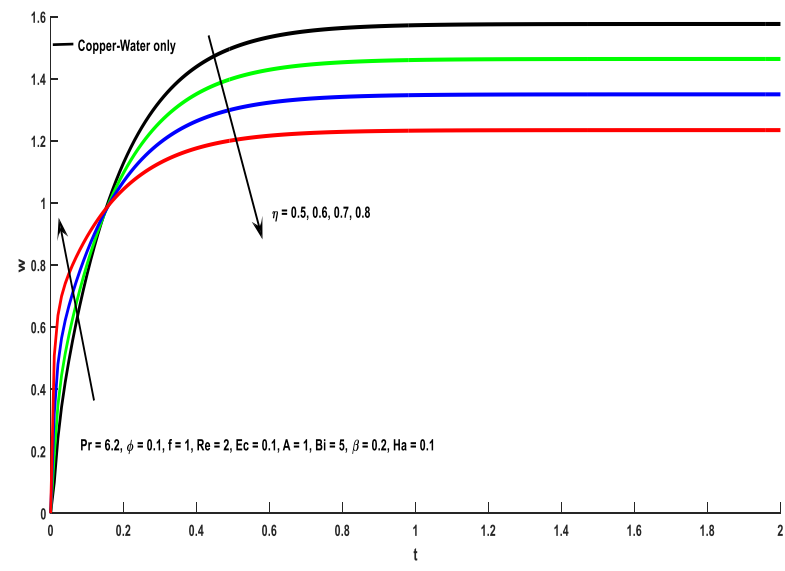

Figure 7: Nanofluid velocity profile with increasing time (t)

It is noticed in figure 7 that nanofluid velocity increases with increase in space and time from $t=0$ up to $t=0.2$, also the nanofluid velocity increases with increase in time from $t=0.2$ up to $t=0.6$ and decreases significantly with increase in space from 0.5 to 0.8 as it approaches the upper plate and thereafter it reaches the steady state from $t=0.6$ to $t=2$ and hence nanofluid velocity alternation at $t=0.2$

From the figure 8 it is clear shown that the nanofluid velocity increases with increasing space at the very lower plate, that is at $t=10$ but so significantly decreases as space and time increases from $t=30-t=100$.

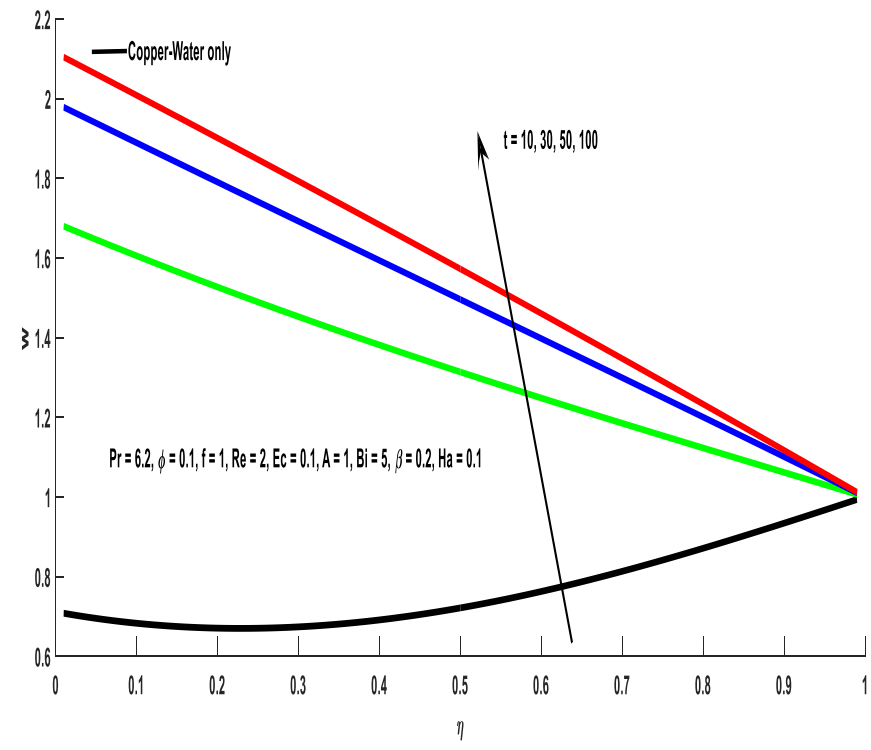

Figure 8: Nanofluid Velocity with increasing space $(\eta)$ 
Observing figure 9, results shows that the velocity of the nanofluid decreases with increase in space of the channel. Also decreases significantly with increasing $\beta$ value from 0.1 to 0.4 as it approaches the upper plate signifying the effect of magnetic field in the channel flow of nanofluid.

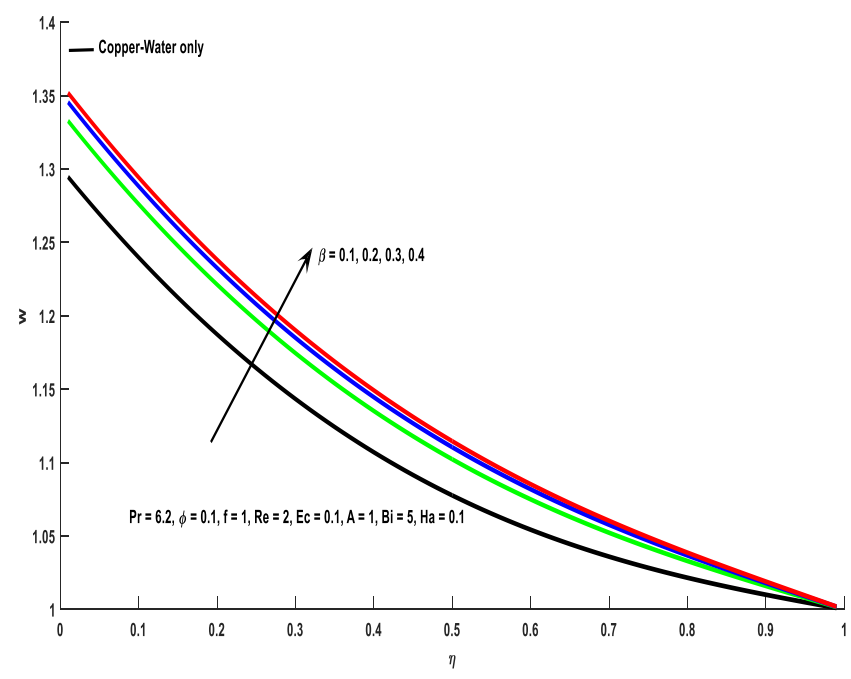

Figure 9: Nanofluid velocity profile with increasing $\beta$

Considering the results in figure 10 we see that the nanofluid velocity tend to increase at high rate when the space increases at a time when no nanoparticles are introduced that is when $\phi=0$ but soon after introducing nanoparticles the rate of nanofluid velocity began to decrease with increase in space and increase in nanoparticles in the nanofluid from $\phi=0.1$ up to $\phi=0.3$.

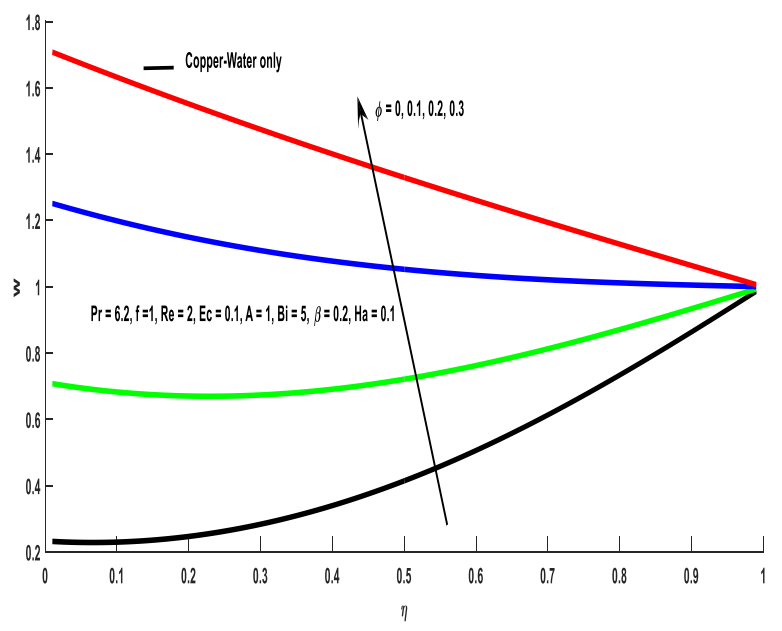

Figure 10: Nanofluid velocity profile with increasing $\phi$

Observing the results shown in figure 11 it is evidently that the nanofluid velocity decreases with increase in Ha and space only from $\eta=0$ to $\eta=0.4$ and thereafter began to increase with increase in Ha and increase in space from $\eta=0.4$ to $\eta=1$. 


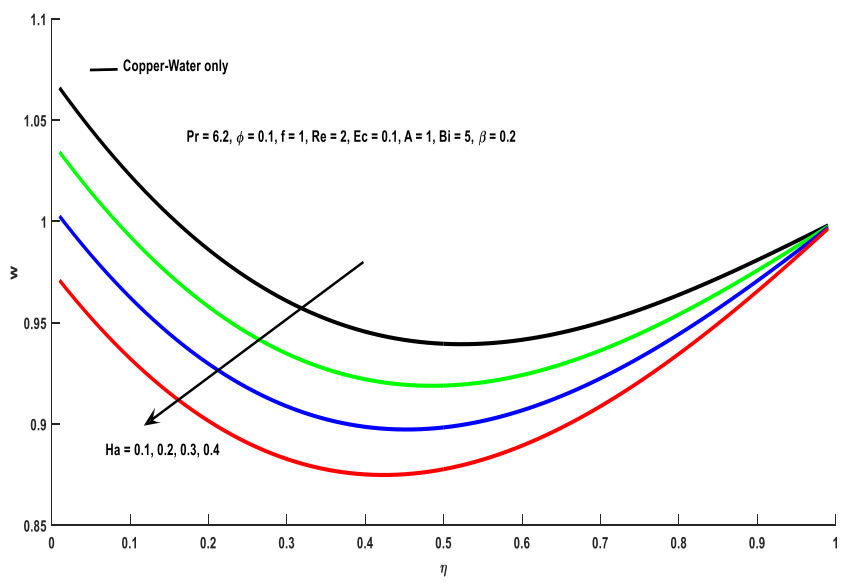

Figure 11: Nanofluid velocity profile with increasing $H a$

From figure 12 it is noted that the nanofluid velocity increases with increasing space and time at the lower plate $t=10$ to both Alumina-water and Copper-water and decreases with space at $t=30, t=50$ and $t=100$. However copper-water nanofluid tends to flow faster than Alumina-water nanofluids until it reaches at $t=100$ where an Alumina-water nanofluid flows faster than Copper-water. This result may be due to high density of Copper nanoparticles as compared to alumina nanoparticles. Also the nanofluid velocity significantly decreases at different rate for alumina-water and Copper-water as space and time increases from $t=30$ to $t=100$.

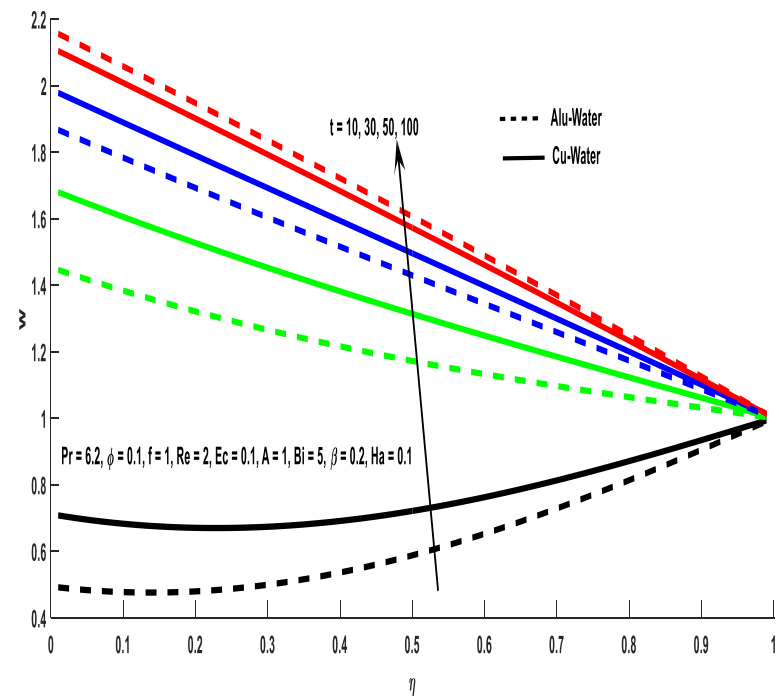

Figure 12: Nanofluid velocity profile with increasing time (t)

It is noticed in figure 13 that nanofluid velocity increases with increase in space and time from $t=0$ up to $t=0.2$ for Copperwater and from $t=0$ up to $t=0.4$ for Alumina-water also the nanofluid velocity increases with increase in time from $t=0.2$ up to $t=0.6$ for Copper-water and from $t=0.4$ to $t=0.8$ for Alumina-water and velocities for the two decreases significantly with increase in space from 0.5 to 0.8 as it approaches the upper plate and thereafter it reaches the steady state from $t=0.6$ to $t=2$ for Copper and from $t=0.8$ to $t=2$ for Alumina-water and hence nanofluid velocity alternation at $t=0.2$ and $t=0.4$ for Copper-water and Alumina-water respectively. 


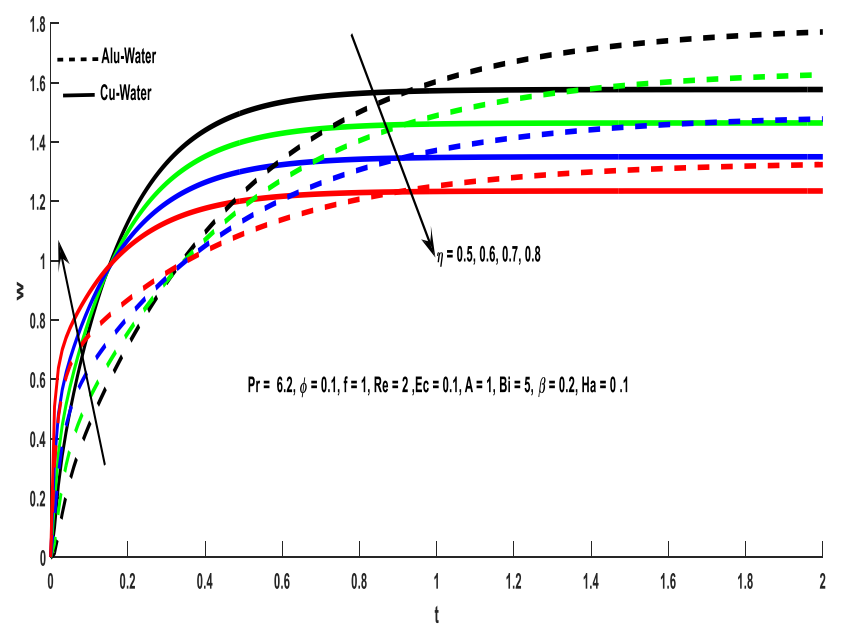

Figure 13: Nanofluid velocity profile with increasing space $(\eta)$

\subsection{Effects of parameter variation on temperature profile}

The results from figure 14 shows that temperature profile tends to increase with increase in space in time interval from $t=0$ up to $t=0.1$ and began to decrease with increase in space in time interval from $t=0.1$ up to $t=0.25$ and thereafter increases again with increase in space at time interval from $t=0.25$ to $t=0.4$ hence wave like motion as it approaches the upper plate.

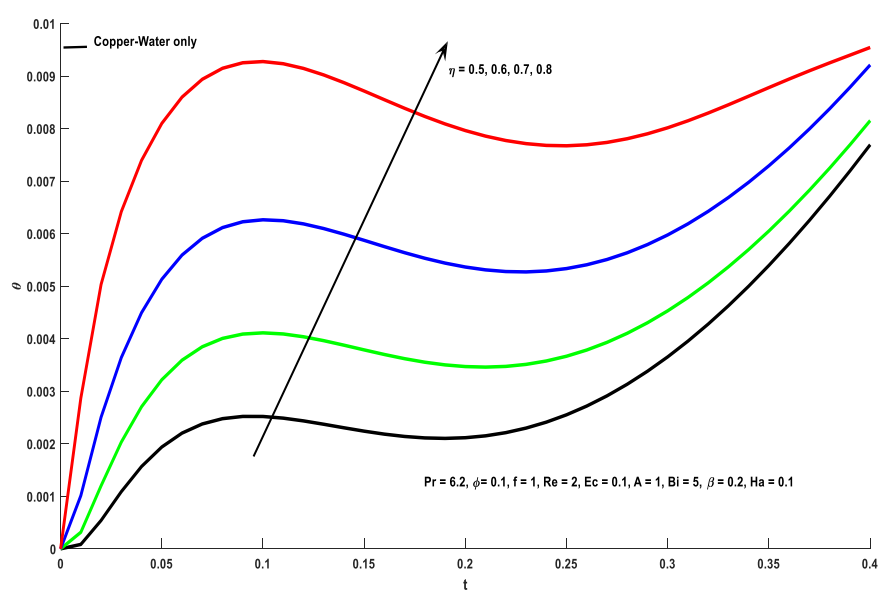

Figure 14: Nanofluid temperature profile with increasing space $(\eta)$

The results in figure 15 shows that the temperature increases with increase in time and space but as it approaches the upper plate the temperature reaches the steady state from $\eta=0.1$ to $\eta=0.4$ at time $t=30, \eta=0.25$ to $\eta=0.4$ at time $t=60$, $\eta=0.3$ to $\eta=0.4$ at time $t=80$ and $\eta=0.35$ to 0.4 at time $t=100$ signifying increase of temperature with time probably due to nanoparticles friction $\phi=0.1$ in the fluid. 


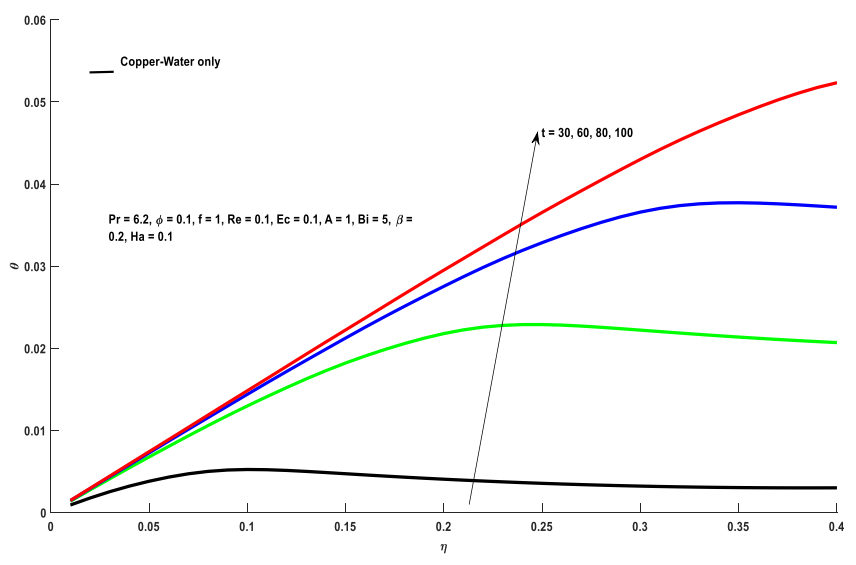

Figure 15: Nanofluid temperature profile with increasing time (t)

Considering figure 16 the results shows that the temperature tend to increase as space and $\beta$ increases in the space interval of $0 \leq \eta \leq 0.4$ and thereafter the temperature undergo oscillation like motion as $\beta$ increases in space interval of $0.4 \leq \eta \leq 1$ possibly due to high random collision between nanoparticles present in the nanofluid as it approaches the upper plate.

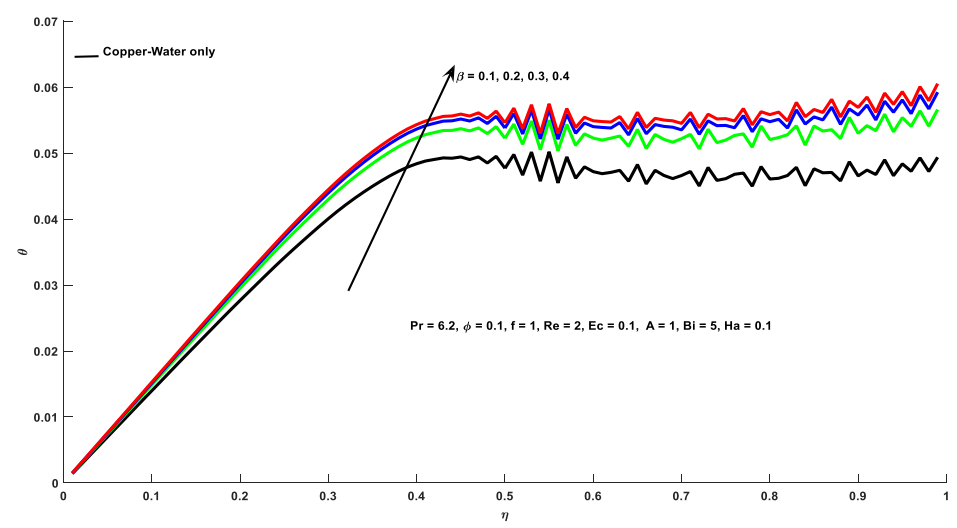

Figure 16: Nanofluid temperature profile with increasing $\beta$

The figure 17 describes the results that the temperature increases with increase in space in the interval of $0 \leq \eta \leq 0.2$, after there, the temperature decreases with increase in space in the interval $0.2 \leq \eta \leq 0.7$ and finally start to increase in oscillation like motion from $\eta=0.7$ with increase in space in the interval $0.7 \leq \eta \leq 1$ however in all cases it decreases significantly with increase in $H a$ from 0.1 to 0.4 in the space interval of $0 \leq \eta \leq 1$.

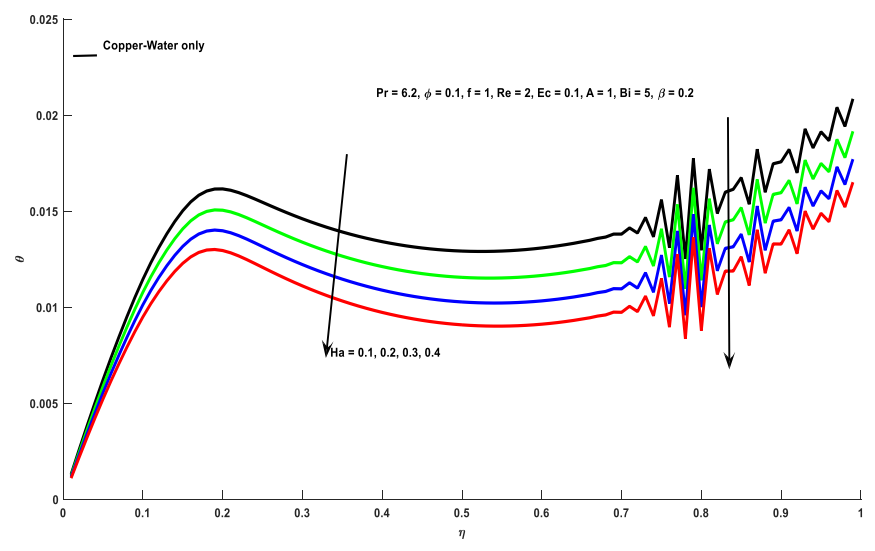

Figure 17: Nanofluid temperature profile with increasing $\mathrm{Ha}$ 
Observing figure 18 the results shows that the temperature increases with increase in space from $\eta=0$ up to $\eta=0.5$, and significantly increases with increase in $\phi$ which can be thought as the effect of friction between the nanoparticles that tend to increase the temperature in the nanofluid but as it approaches the upper plate the temperature start to perform oscillation motion in the steady state from $\eta=0.5$ to $\eta=1$.

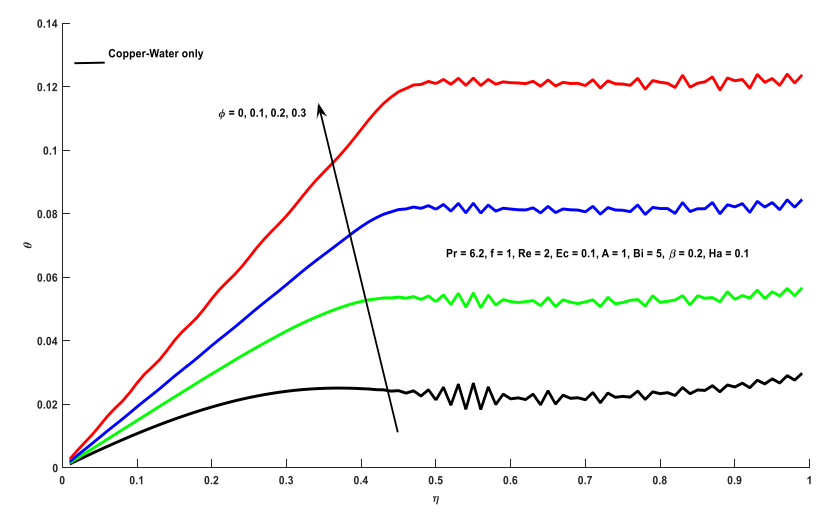

Figure 18: Nanofluid temperature profile with increasing $\phi$

The results in figure 19 shows that the temperature increases with increase in time and space for both Alumina-water and Copperwater however at different rate up to time interval $0.1 \leq t \leq 0.2$ in which Alumina-water has high temperature than Copperwater and subsequently the temperature tend to decrease with increase in time and space at different rates in which temperature for Alumina- water decreases faster than that of Copper-water in the interval between $0.1 \leq t \leq 0.3$. And very interesting result is observed in the time of $0.4 \leq t \leq 1$ where by the temperature of Alumina-water tends to increase so faster than that of Copperwater signifying that alumina-water absorbs heat faster than Copper-water simply because of the differences in their materials with different specific heat capacities.

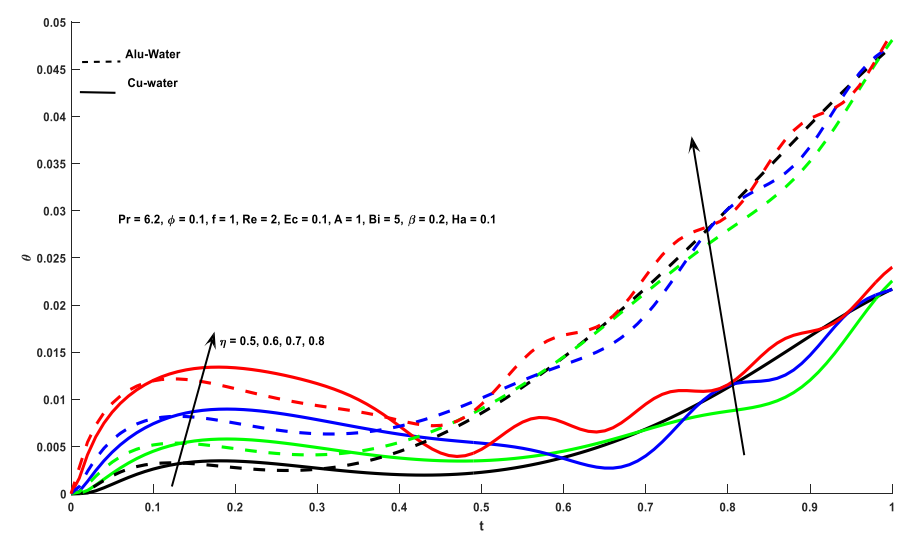

Figure 19: Nanofluid temperature profile with increasing space $(\eta)$

Figure 20 describes the results of temperature variation with combined nanofluids of Alumina-water and Copper-water in which the temperature of Alumina-water tend to increase faster than Copper-water with increase in time and space in between the interval $0 \leq \eta \leq 0.1$ at time $\mathrm{t}=30,0 \leq \eta \leq 0.2$ at time $\mathrm{t}=60,0 \leq \eta \leq 0.3$ at time $\mathrm{t}=80$ and $0 \leq \eta \leq 0.4$ at $\mathrm{t}=100$. Thereafter the temperature Alumina-water tends to decrease faster than that of the Copper-water as time and space increases toward the steady state under which tends to oscillate with temperature of Copper-water higher than that of the Alumina-water. 


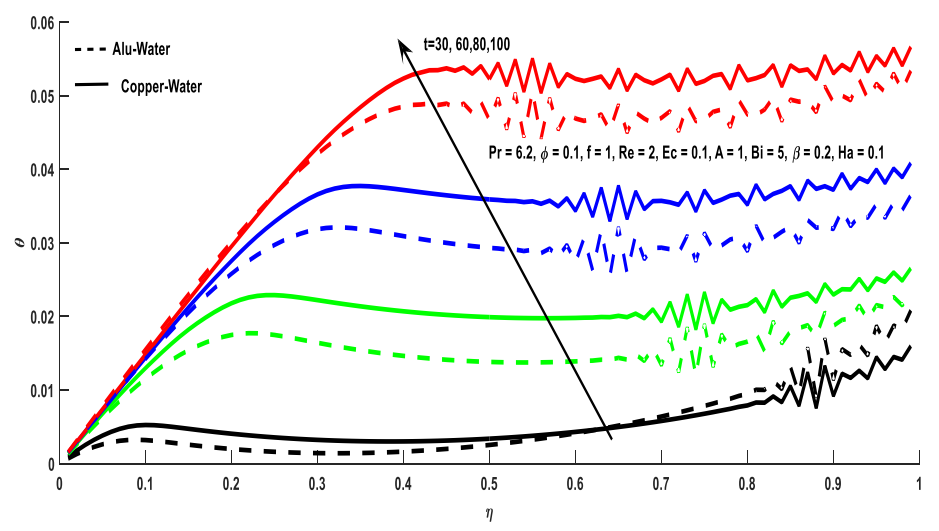

Figure 20: Temperature profile with increasing time (t)

\section{CONCLUSION}

The effect of magnetic field on second law analysis for magneto-hydrodynamic (MHD) permeable channel flow with convective cooling with Copper $(\mathrm{Cu})$ and Alumina $\left(\mathrm{Al}_{2} \mathrm{O}_{3}\right)$ as nanofluids was investigated. Using a semi-discretization finite-difference method together with a Runge-Kutta-Fehlberg integration scheme implemented on computer using Matlab, the nonlinear governing partial differential equations were transformed into initial value ODEs and then solved numerically. The nanofluid velocity profile and nanofluid temperature profiles were discussed as a result of the following conclusions;

Alumina-water velocity profile resembles that of Copper-water velocity profile likewise to nanofluid temperature profiles however the significant difference on the rate of variation was observed as a result of their differences in densities and specific heat capacities. The $\mathrm{Al}_{2} \mathrm{O}_{3}$-water nanofluid tended to flow quicker than $\mathrm{Cu}$-water nanofluid and the velocity profile increased with $H a$ but decreased with $\varphi$ and $\beta$.

\section{REFERENCES}

1. Baskaya, E., Komurgoz, G. and Ozkol, I. (2017) 'Investigation of Oriented Magnetic Field Effects on Entropy Generation in an Inclined Channel Filled', pp. 1-16. doi: 10.3390/e19070377.

2. Mkwizu, M. H., Makinde, O. D. and Nkansah-Gyekye, Y. 'Second Law Analysis of Buoyancy Driven Unsteady Channel Flow of Nanofluids with Convective Cooling', Applied and Computational Mathematics, 4(3), p. 100. doi: 10.11648/j.acm.20150403.12.

3. Kareem, S. O. et al. (2017) 'Entropy Generation Rate in Unsteady Buoyancy-Driven Hydromagnetic Couple Stress Fluid Flow Through a Porous Channel', International Journal of Pure and Apllied Mathematics, 115(2). doi: 10.12732/ijpam.v115i2.9.

4. Makinde, O. D. and Tshehla, M. S. (2017) 'Irreversibility Analysis of MHD Mixed Convection Channel Flow of Nanofluid with Suction and Injection’, 13(9), pp. 4851-4867.

5. Marie, M. and Couette, A. (no date) 'Analysis of entropy generation rate in a hydromagnetic Couette flow of nanofluids inside a rotating channel'.

6. Mkwizu. M H, Matofali, A. X. and Ainea, N. (2018) 'Entropy generation in a variable viscosity transient generalized Couette flow of nanofluids with Navier slip and convective cooling', 5(4), pp. 20-29.

7. Medina, A. (2016) 'Numerical investigation of entropy generation in microchannels heat sink with different shapes Numerical investigation of entropy generation in micro- channels heat sink with different shapes'. doi: 10.1088/1757899X/147/1/012134.

8. Mkwizu, M. H. and Makinde, O. D. (2015) 'Numerical investigation into entropy generation in a transient generalized Couette flow of nanofluids with convective cooling', 40(October), pp. 2073-2093.

9. Mkwizu, M. H., Makinde, O. D. and Nkansah-Gyekye, Y. (2015) 'Effects of Navier slip and wall permeability on 
International Journal of Advances in Scientific Research and Engineering (ijasre), Vol 6 (5), May-2020

entropy generation in unsteady generalized Couette flow of nanofluids with convective cooling', UPB Scientific Bulletin, Series D: Mechanical Engineering, 77(4), pp. 201-216. doi: 10.1007/s00125-009-1361-4.

10. Vyas, P. and Srivastava, N. (2013) 'Radiation effects on dissipative magnetohydrodynamic couette flow in a composite channel', Zeitschrift fur Naturforschung - Section A Journal of Physical Sciences, 68(8-9), pp. 554-566. doi: 10.5560/ZNA.2013-0038. 